\title{
Psychological Factors and Family Troubles among Adolescents with Drug Use Disorders
}

\author{
NORHAN A. EL-FALLAH, M.Sc.; EL-SAYED A. GAD, M.D.; ADEL A. BADAWY, M.D. and \\ SHEREEN D. ABO HAMAR, M.D.
}

The Department of Neuropsychiatry, Faculty of Medicine, Tanta University

\begin{abstract}
Background: Substance use among adolescents is a complex and multidimensional problem. Parental substance use, family conflict, poor family management practices and affiliation with peers using illicit drugs are important risk factors for addiction.

Aim of Study: The aim of this study is to assess impulsivity, peer relationships and parent relationship among adolescents with substance use disorders.

Subjects and Methods: Eighty adolescents were included in this study, 40 patients with substance use disorder and 40 healthy adolescents as a control group. All subjects of the study were subjected to: Drug abuse history, Arabic Version of (MINI-KID), IQ assessment, Substance Use Risk Profile Scale (SURPS), Socioeconomic Status Scale for Health Research in Egypt, questionnaire of parental attitudes as realized by adolescents and Inventory of Parents and Peer Attachment.

Results: There was no statistically significant difference between both groups as regards age, sex and residency. Fortyfive percent of adolescents with substance abuse came from single parent families. The patients had significantly more positive family history of substance use disorders $(p=0.012)$ and more family history ( $p=0.013)$ of psychiatric disorders. Tramadol is the most common abused substance $37.5 \%$. The most common psychiatric co-morbidities in patients group were conduct disorder (22.5\%) and major depressive disorder $(15 \%)$. Impulsivity, anxiety sensitivity and hopelessness were significantly increased among patients group than control group ( $p=0.001),(p=0.006) \&(p=0.001)$ respectively. Fathers of patients showed significantly higher consistency with their sons $(p=0.021)$ as well as higher rejection $(p=0.002)$, while the mothers of patients showed significantly higher independency $(p=0.005)$ than control group. Adolescent with substance use disorders had significant less trust and communication with their friends $(p=0.009),(p=0.001)$. Patients has significantly more friend with history of substance use disorders $(p=0.011)$.
\end{abstract}

Conclusions: Poor family management practices and relationships to peers using illicit drugs are important risk factors for addiction. There are certain psychiatric disorders associated with substance use such as conduct disorder and

Correspondence to: Dr. Norhan A. El-Fallah, The Department of Neuropsychiatry, Faculty of Medicine, Tanta University depression. There are also some psychological factors associated with substance use disorder such as impulsivity, hopelessness and sensation seeking.

Key Words: Substance use - Family troubles - Impulsivity Adolescent-Peers - Conduct disorder.

\section{Introduction}

SUBSTANCE use refers to the harmful or hazardous use of psychoactive substances, including alcohol and illicit drugs. Substance use is a complex and multidimensional problem which poses a threat to the health, social and economic levels of families and communities [1].

Adolescence is a period of increased risk-taking behavior, often accompanied by first experiences with alcohol and drug use [2], a teen's brain develops somewhat unevenly, from back to front. This may help explain their endearingly quirky behavior but also makes them prone to risk-taking and substance use [3] .

Adolescent substance use is influenced by many factors, such as family, school, peers, psychological factors, media, and community [4].

Family structure such as broken homes and single-parent families and relationship among the family members were found to have significant influence on a child's behavior regarding substance use. Parenting styles that include low parental involvement, inconsistent discipline, and poor monitoring of adolescents can lead to teens having substance use disorders [5].

Also, individuals with relationships to peers using illicit drugs have an increased risk of using drugs themselves. Furthermore, having delinquent peers or peers expressing antisocial attitudes is also associated with increased risk of drug use [6] 
Several individual and personality factors such as sensation seeking, anxiety sensitivity and poor impulse control are linked to adolescent addiction [7]. There is also high prevalence of mood disorders (especially depression) $[8]$ and behavior disorders (conduct disorder and ADHD) among adolescents with substance use disorder [9].

Aim of the work: Is to assess impulsivity, peer relationships and parent relationship among adolescents with substance use disorders.

\section{Subjects and Methods}

The current case control study was carried out at Tanta University both Neuropsychiatry Department ant Psychiatry, Neurology and Neurosurgery Center of Tanta University from August 2016 to February 2018.

\section{Subjects:}

The study included two groups. The patients group included forty adolescents (6 females and 34 males, their ages were between 15 and 19 years (mean $\pm \mathrm{SD}=17.95 \pm 1$ year). All of them met DSM5 diagnostic criteria [10] for substance use disorders and had positive urine test for substance of abuse. Tramadol is the most common abused substance $37.5 \%$ followed by heroin $27.5 \%$ then polysubstance abuse $22.5 \%$ and hashish $12.5 \%$. The duration of substance use disorder range between 0.5 to 5 years with mean duration of $1.86 \pm 0.96$ years.

Patients with intellectual disability and other medical disorders were excluded. The control group included 40 healthy adolescents without any behavioral complaints. They were 10 females and 30 males; their mean age was $18.33 \pm 1.25$ year (range was 15 to 19 years). Both groups were matched as regards age $(t=1.25, p=0.215)$ and $\operatorname{sex}\left(\chi^{2}=1.25\right.$, $p=0.246$ ).

\section{Methods:}

A written informed consent was obtained from every one of both groups after explaining the steps of the study and its aim. Data about subjects and their families were collected by clinical sheet prepared by the researchers. The Mini International Neuropsychiatric Interview for Children and Adolescents (MINIKID), Arabic Version [11,12], was used for interviewing the adolescents and for diagnosis of any comorbid psychiatric disorders. IQ assessment by using Wechsler Adult Intelligence Scale (WAIS) [13] .

\section{Personality assessment:}

The personality character of the adolescents was assessed by The Substance Use Risk Profile
Scale (SURPS) Arabic version [14]. The Substance Use Risk Profile Scale (SURPS) is based on a model of personality risk for substance abuse in which four personality dimensions (hopelessness, anxiety sensitivity, impulsivity, and sensation seeking) are hypothesized to differentially relate to specific patterns of substance use. The SURPS has 23 items and is intended to measure susceptibility to or risk of engaging in addictive behaviors. The scale is composed of four subscales measuring the four personality dimensions.

The socioeconomic state of all subjects was assessed by Socioeconomic Status Scale for health research in Egypt [15]. The scale is a modified version of Fahmy and El-Sherbini scale socioeconomic status, the subscales has 7 domains which are (education and cultural domain, occupation domain, family possessions domain, family domain, home sanitation domain, economic domain and health care domain) with a total score 84 . Cronbach alpha of the scale is 0.66 . Kappa coefficient 0.76 . sociodemographic levels were classified into very low, low, middle and high according to the quartiles of the score calculated as follows: Very low $<26$, low $=26-36$, middle $=37-46$, high $>46$.

\section{Parental attitude as realized by adolescents:}

The questionnaire of parental attitudes as realized by adolescents [16] was used for assessment of attitude of adolescents towards their parents. This scale includes 40 items divided equally into 4 subscales so that the subject replies to each phrase twice, first is that represents his perception of the father's parental trend while the other reflects the mother's parental trend in addition to a total score. The subscales are: Dependency-independence, inconsistency-consistency, rejection-receptivity, discrimination-equality and total score.

\section{Peer relationships:}

Assessment of the peer relationship by use of Inventory of Parents and Peer Attachment (IPPA) Arabic version [17]. The IPPA measures adolescent peer attachment styles by assessing the following three dimensions: Trust (the adolescents' trust that peers understand and respect their needs and desires), communication (which refers to adolescents' perceptions that peers are sensitive and responsive to their emotional states and assessing the extent and quality of involvement and verbal communication with them), and alienation (which refers to adolescents' feelings of isolation, anger, and detachment experienced in attachment relationships with peers). The total score measure security attachment. 
The research was approved by the Ethical and Research Committee of Tanta University, Faculty of Medicine.

\section{Statistical analysis:}

All data were recorded, tabulated, and analyzed on SPSS (Version 21; SPSS Inc., Chicago, Illinois, USA). Descriptive statistics were obtained as means and SD. Student's $t$-test was used for independent data. Qualitative data were analyzed using Pearson's w-test. $p$-value was used to indicate the level of significance. A $p$-value less than 0.05 was considered significant.

\section{Results}

Most of the adolescents with substance use disorders in the studied population were belonging to vocational secondary schools. Educational level was significantly higher in control group than patient group $(\chi=23.900, p=<0.001)$. While adolescents with manual work are significantly more among patients than control group, adolescents without job are significantly more among control group $(\chi=9.326, p=0.009)$ (Table 1$)$.

Table (1): Demographic data of the studied groups.

\begin{tabular}{|c|c|c|c|c|}
\hline & $\begin{array}{l}\text { Patient } \\
\text { group }\end{array}$ & $\begin{array}{l}\text { Control } \\
\text { group }\end{array}$ & $\chi^{2}$ & $p$ \\
\hline $\begin{array}{l}\text { Residence: } \\
\text { - Urban } \\
\text { - Rural }\end{array}$ & $\begin{array}{l}22(45 \%) \\
18(45 \%)\end{array}$ & $\begin{array}{l}18(45 \%) \\
22(55 \%)\end{array}$ & 0.800 & 0.371 \\
\hline $\begin{array}{l}\text { Occupation: } \\
\text { - Unemployed } \\
\text { - Manual } \\
\text { - Clerical }\end{array}$ & $\begin{array}{ll}25 & (62.5 \%) \\
12 & (30 \%) \\
3 & (7.5 \%)\end{array}$ & $\begin{array}{l}36(90 \%) \\
2(5 \%) \\
2(5 \%)\end{array}$ & 9.326 & $0.009 *$ \\
\hline $\begin{array}{l}\text { Educational level: } \\
\text { - Illtreat } \\
\text { - Primary school } \\
\text { - Preparatory school } \\
\text { - Secondary school } \\
\text { - Vocational school } \\
\text { - University students }\end{array}$ & $\begin{array}{ll}3 & (7.5 \%) \\
3 & (7.5 \%) \\
6 & (15 \%) \\
9 & (22.5 \%) \\
13 & (325 \%) \\
6 & (15 \%)\end{array}$ & $\begin{array}{l}0 \\
0 \\
6(15 \%) \\
2(5 \%) \\
7(17.5 \%) \\
25(62 \%)\end{array}$ & 23.900 & $<0.001^{*}$ \\
\hline
\end{tabular}

Forty-five percent of adolescents with substance abuse came from single parent families while $17.5 \%$ of the control group came from single parent families and the difference between the 2 groups was statistically significant $(\chi=10.39$ and $p=$ $0.016)$. Both substance use disorders $\left(\chi_{2}^{2}=6.28\right.$, $p=0.012)$ and psychiatric disorders $(\chi=6.14$, $p=0.013$ ) are more prevalent among patients' group (Table 2).

Comorbid psychiatric disorders are common among adolescents with substance use disorders, $47.5 \%$ of them had other psychiatric disorders.
The most common diagnosis among the studied adolescents was conduct disorder $(22.5 \%)$ and major depressive disorder (15\%) in patients' group (Table 3).

Table (2): Family structure, family history of psychiatric disorders and substance abuse among the groups.

\begin{tabular}{lllll}
\hline & $\begin{array}{c}\text { Patient } \\
\text { group }\end{array}$ & $\begin{array}{l}\text { Control } \\
\text { group }\end{array}$ & $\chi^{2}$ & $p$ \\
\hline Extended family & $2(5 \%)$ & 0 & 10.39 & $0.016^{*}$ \\
Nuclear family & $20(50 \%)$ & $33(82.5 \%)$ & & \\
Only mother & $15(37.5 \%)$ & $5(12.5 \%)$ & & \\
Only father & $3(7.5 \%)$ & $2(5 \%)$ & & \\
Substance abuse & $10(25 \%)$ & $2(5 \%)$ & 6.28 & $0.012^{*}$ \\
Psychiatric disorders & $8(20 \%)$ & $1(2.5 \%)$ & 6.14 & $0.013^{*}$ \\
\hline
\end{tabular}

*: Significant difference.

Table (3): Comorbid psychiatric disorders among patients.

\begin{tabular}{lcl}
\hline \multirow{2}{*}{ MINI-KID interview } & \multicolumn{2}{c}{ Patient group } \\
\cline { 2 - 3 } & Numbers & $\%$ \\
\hline Panic disorder & 1 & 2.5 \\
Generalized anxiety disorder & 2 & 5 \\
OCD & 1 & 2.5 \\
ADHD with hyperactivity & 1 & 2.5 \\
Conduct disorder & 9 & 22.5 \\
Major depressive disorder & 6 & 15 \\
Bipolar disorder & 1 & 2.5 \\
\hline Total & 19 & 47.5 \\
\hline *: Significant difference. & \multicolumn{2}{|l}{}
\end{tabular}

The personality dimension of impulsivity, anxiety sensitivity and hopelessness were significantly increased among patients' group than control $(p=$ $0.001),(p=0.006) \&(p=0.001)$ respectively. The sensation seeking dimension was not significantly different among the two groups $p=0.59$ ). The mean scores of the Substance Use Risk Profile Scale (SURPS) was significantly higher in the patients than the control $\left(\chi^{2}=6.194, p<0.001\right)$ Fig. (1).

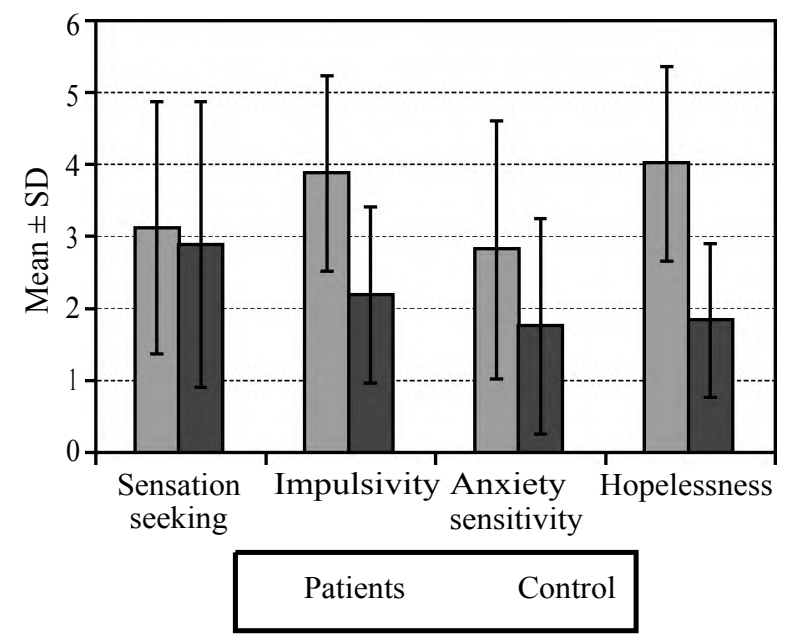

Fig. (1): Results of the Substance Use Risk Profile Scale (SURPS) of the studied groups. 
The fathers of patients showed significantly higher consistency with their sons $\left(\chi_{2}^{2}=2.352, p=\right.$ $0.021)$ as well as higher rejection $\left(\chi^{2}=-3.247, p=\right.$ $0.002)$ than control group. The mean scores of the questionnaire of parental attitudes as realized by adolescents of both groups were non significantly different $\left(\chi^{2}=0.28, p=0.774\right)$. As regards dependency-independency, the mothers of patients showed significantly higher independency $\left(\chi^{2}=2.925\right.$, $p=0.005)$, while there was no statistically significant difference between all other subscales of the questionnaire between both groups (Table 4).

Table (4): Parenting style as perceived by adolescents (both mother and father).

\begin{tabular}{|c|c|c|c|c|c|c|c|c|}
\hline & \multicolumn{2}{|c|}{$\begin{array}{l}\text { Dependency- } \\
\text { independence }\end{array}$} & \multicolumn{2}{|c|}{$\begin{array}{c}\text { Inconsistency- } \\
\text { consistency }\end{array}$} & \multicolumn{2}{|c|}{ Rejection receptivity } & \multicolumn{2}{|c|}{$\begin{array}{l}\text { Discrimination- } \\
\text { equality }\end{array}$} \\
\hline & Mean \pm SD & $p$ & Mean \pm SD & $p$ & Mean \pm SD & $p$ & Mean \pm SD & $p$ \\
\hline Patients (maternal) & $14.4 \pm 3.9$ & $0.005^{*}$ & $14.5 \pm 5.3$ & 0.12 & $14.1 \pm 3.4$ & 0.25 & $13.1 \pm 3.1$ & 0.23 \\
\hline Control (maternal) & $11.5 \pm 4.7$ & & $12.9 \pm 4.7$ & & $15.1 \pm 4.2$ & & $14.1 \pm 4.2$ & \\
\hline Patients (paternal) & $11.7 \pm 4.4$ & 0.34 & $14.9 \pm 3.5$ & $0.02 *$ & $10.7 \pm 4.9$ & $0.002 *$ & $12.6 \pm 3.2$ & 0.5 \\
\hline Control (paternal) & $10.8 \pm 4.2$ & & $12.8 \pm 4.6$ & & $13.9 \pm 4.0$ & & $13.1 \pm 3.8$ & \\
\hline
\end{tabular}

*: Significant difference.

The IPPA measures adolescent peer attachment styles by assessing the following three dimensions: Trust, communication, and alienation. While the scores of both trust $(t=-2.69, p=0.009)$ and communication $(t=-3.48, p=0.001)$ are significantly higher in the control group than patients, there was no significant difference between both groups as regards alienation. The total score of the questionnaire was significantly higher in the control group ( $t=-2.747, p=0.007)$. So, the control group has more secure attachment with their peers than the patients (Table 5).

Table (5): Peer attachment of the studied adolescents assessed by Inventory of Parents and Peer Attachment (IPPA).

\begin{tabular}{lllcl}
\hline & Patients group & Control group & $t$ & $p$ \\
\hline Trust & $31.250 \pm 7.189$ & $34.800 \pm 4.244$ & -2.690 & $0.009^{*}$ \\
Communication & $25.050 \pm 7.739$ & $29.550 \pm 2.611$ & -3.484 & $0.001^{*}$ \\
Alienation & $20.075 \pm 5.071$ & $20.350 \pm 4.452$ & -0.258 & 0.797 \\
\hline Total score & $76.375 \pm 16.940$ & $84.700 \pm 8.968$ & -2.747 & $0.007^{*}$ \\
\hline
\end{tabular}

*: Significant difference.

On correlating dependence-independence subscale of paternal parenting of the patient group with personality risk for addiction, there was only one statistically significant ( $r=0.391, p=0.013$ ) positive correlation with anxiety sensitivity, this means that independent paternal parenting style of the patient group increases anxiety sensitivity of the patients. There was also one statistically significant ( $r=-0.427, p=0.006$ ) negative correlations between paternal inconsistency-consistency subscale of the patient group and anxiety sensitivity, this means that consistent paternal parenting style of the patient group decreases anxiety sensitivity of the patients.

On correlating dependence-independence subscale of maternal parenting with personality risk for addiction, there were statistically significant positive correlation with sensation seeking ( $r=$ $0.329, p=0.038$ ), anxiety sensitivity ( $r=0.426, p=$
0.006) and total score of substance use risk profile scale $(r=0.330, p=0.038)$. This means that independent maternal parenting style of the patient group increases sensation seeking, anxiety sensitivity and personality risk for addiction.

The discrimination-equality subscale of maternal parenting in the patient group had statistically significant ( $r=0.314, p=0.048$ ) positive correlation with anxiety sensitivity which means that equality in maternal parenting styles increases anxiety sensitivity in the patient group.

\section{Discussion}

\section{Occupation of the studied adolescents:}

Adolescents without occupation are significantly more among control group (90\%) than patients $(62.5 \%),(p=0.009)$. This is supported by the study 
of Li-Tzy et al., [11] who found an association between being employed and increased rates of recent substance use. In contrast to the present study, Bachman et al., [12] found that adolescents who become unemployed between 20 and 25 years of age are more likely to have smoked heavily, used marijuana, or used cocaine.

Regarding type of occupation, manual workers $(30 \%)$ were more than clerical workers $(7.5 \%)$ in patient group. This means that manual work increases susceptibility to drug abuse. This is supported by the study of Gavioli et al., [13] and Mikhail et al., [14] who found substance use disorders among construction workers. Mental distress, risky behaviors, and injury rates are high in the male dominated US construction industry. Limited secondary data and national epidemiologic studies suggest that drug abuse remains high within this worker population [15]. This is probably due to their misbelieve that such drugs could increase their work abilities and productivity.

\section{Educational level of the studied adolescents:}

The educational level was significantly higher in control group than patient group $\left(X^{2}=23.900\right.$, $p=<0.001)$. This means that high educational level is considered a protective factor against substance use disorders. This is supported by the study of Hamdi et al., [16] who showed that the less educated people were more common users of substance(s). The same was found in USA: In 2014, annual prevalence of use of any illicit drug was 39\% for college students and $44 \%$ among the non college respondent [17].

\section{Family structure of the studied adolescents:}

Families with single parent include more adolescents with substance use disorders. Results of current study revealed that the absence of father was highly related to substance use disorders (37.5\%) compared with absence of mother $(7.5 \%)$. This is supported by the study of El-Awady et al., [18] who found that absence of father was highly related to substance use disorders (92\%). Hemovich et al., [19] reported that youth from single-parent families engaged in significantly higher levels of substance use than those from dual parent households. This can be explained that single parents, on average, would have less time to monitor their children consistently and intensively.

\section{Family history of drug abuse:}

Family history of drug abuse was more in the patient group; as 10 (25\%) of the patient group while only $2(5 \%)$ of the control group had positive history of drug abuse and this was statistically significant ( $p=0.012)$. This indicates that family history of drug abuse makes adolescents more liable to substance use disorders. This is supported by the study of Effat et al., [20] who found that (72.8\%) of the case group had positive family history of substance use disor ders. Also El-Awady et al., [18] and Mohamed et al., [21] found that $(25 \%)$ of the participants reported that their fathers had used drug.

\section{Family history of psychiatric disorders:}

As regards family history of psychiatric disorders, $8(20 \%)$ of the patients had positive family history of psychiatric disorders compared to 1 $(2.5 \%)$ of the control group and the difference between the two groups was statistically significant $(p=0.013)$. This indicates that family history of psychiatric disorders makes adolescents more liable to substance use disorders.

This is supported by the study of Effat et al., [20] who found that $(22.2 \%)$ of the case group had positive family history of psychiatric disorders. Sitnick et al., [22] noted that there is an association between clinical levels of maternal depression and later substance use problems, with children of a clinically depressed mothers.

\section{Psychiatric co morbidity of the patients:}

As regards psychiatric co morbidity, we found that $(47.5 \%)$ of patients have at least one other co morbid psychiatric disorder. Armstrong \& Costello [23] found that two out of every three adolescents with substance use disorder have at least one other co-morbid diagnosable psychiatric disorder.

Moreover, in such patients, the signs and symptoms of psychoactive substance intoxication or withdrawal are often difficult to distinguish from those of a concurrent psychiatric disorder, which may serve as an indication of the severity of substance abuse [24]

\section{Prevalence of conduct disorder:}

Regarding conduct disorder, the results of the present study showed that the most frequently cooccurring co-morbid psychiatric disorders among adolescents of the patient group were conduct disorder, we found that $9(22.5 \%)$ of patients were diagnosed to have conduct disorder as a psychiatric co morbidity. This indicates that conduct disorder is a well-known predictor of substance use disorder among adolescents in general [25]. This result is similar to the study of Effat et al., [20] who found that conduct disorder criteria were met by 57 
$(71.3 \%)$ of the case group versus $10(12.5 \%)$ of the control group.

\section{Prevalence of depression:}

MINI-KID interview showed that $6(15 \%)$ of the patients had co morbid major depressive disorder, this is in agreement with another studies by Salah et al., [26]; Armstrong \& Costello, [23] and Effat et al., [20] who found that substance abuse was highly associated with depression.

It is likely that the high prevalence of these disorders occurring together reflects, in part, overlapping genetic, environmental and neurobiological factors, substance use may occur in attempts to improve mood in depressed subjects, however it is possible that chronic substance use leads to neurobiological changes that increase vulnerability for depression [27]. Also, Fatseas et al., [8] found that a current mood and/or anxiety disorder increased craving intensity and thereby the risk for substance use. Gamble et al., [28] found that there are associations between depression or anxiety disorders with more substance use and poorer treatment outcome among patients with substance addiction.

\section{Psychological factors associated with substance} use disorders:

Impulsivity, anxiety sensitivity and hopelessness were significantly increased among patient group than control group ( $p=0.001),(p=0.006)$ and $(p=$ $0.001)$ respectively.

\section{Impulsivity:}

Impulsive youth are more likely to experiment drugs, use drugs regularly and develop substanceuse disorders. This is in agreement with recent study by Hamdan-Mansour [29] who found that impulsivity personality trait is a significant predictors of substance use among university students. Kirisci et al., [30] conducted a longitudinal study showing that childhood 'neurobehavioral disinhibition' directly predicted substance use disorder at age 22. Monterosso et al., [31] found that there is evidence that both cocaine and methamphetamine abusers perform more poorly than control subjects on the Stop Task.

Several studies have found that acute doses of abused drugs affect performance on the Stop Task. De Wit et al., [32] found that alcohol increases Stop time (i.e. the ability to inhibit responses) without affecting Go time in healthy young adults, consistent with the idea that alcohol impairs inhibitory control.
In contrast, amphetamine decreased stop times, i.e. improved the ability to inhibit pre potent responses, this is consistent with the decrease in impulsivity that is also observed with this class of drugs in children treated for ADHD [33]

People who are highly impulsive and those diagnosed with ADHD are at increased risk for substance use disorders. Recent research implicates a variant of the gene for a protein called cAMPResponse Element Modulator (CREM) in these associations [34].

\section{Hopelessness:}

Hopelessness was significantly increased among patient group than control group ( $p=0.001)$. So, hopelessness is associated with substance abuse in adolescents.

The same results were found in the study of Jaffee \& D'Zurilla [35] who said that in adolescents who have the expectation that negative events may occur (hopelessness personality), these characteristics impair the ability to define problems, as well as to generate solutions. This impairment, in turn, may lead to increased substance use in these individuals.

Also, Malmberg et al., [36] found that hopelessness and sensation seeking are indicative of having ever used alcohol in early adolescence.

One possible explanation is that hopelessness leads adolescents to initiate substance use as a means to cope with negative thoughts. Another explanation is that early childhood problems (e.g., family violence, unorganized family environments, antisocial behavior) can lead to both negative affect and an early onset of substance use [37].

On the other hand, Sadek et al., [38] found that the hopelessness scores did not statistically correlate with concurrent abuse of opiates, oxycodone, or cocaine.

\section{Sensation seeking:}

There were no significant differences between patient group and control group regarding sensation seeking ( $p=0.592)$. In contrast to our study, Malmberg et al., [36] found that there is a clear linkage between two hopelessness and sensation seeking and ever-used tobacco in early adolescence and also showed that sensation seeking is associated with an early onset of cannabis use. It is thought that sensation seekers use substances for the euphoric/intoxicating effects [39]. So, it might be that 
especially sensation seekers attribute such characteristics to different substances (e.g., cannabis) and are therefore more likely to initiate use of a certain substance [36].

The difference between the results of our study and these results may be due to smaller number of participants in our study. Another explanation is that sensation seeking is a common personality trait in this age group but it might encourage adolescent to be engaged in useful activities instead of hazardous activities such as substance abuse.

\section{Anxiety sensitivity:}

Anxiety sensitivity was significantly increased among patient group than control group ( $p=0.006)$. This means that anxiety sensitivity is considered a risk factor for substance use disorders. This is supported by the study of Schmidt et al., [40] and Conrod et al., [41] who reported that anxiety sensitivity appears to be a risk factor for alcohol use disorders. High anxiety sensitivity individuals may thus be motivated to use alcohol to reduce, control, and/or avoid their fear of aversive arousal sensations and the sensations themselves [42].

In contrast to the current study, Malmberg et al., [36] found a negative association between anxiety sensitivity and alcohol use. This can be explained that this different study was done on alcohol and when highly anxiety sensitive individuals have no prior experience with alcohol they also do not know if drinking alcohol leads to unusual body sensations, which might keep them from drinking. Also, it could be that highly anxiety sensitive individuals are more anxious in general, and are for instance afraid of losing control when drinking.

Anxiety sensitivity is clearly relevant to negative-reinforcement models of substance use, such that heightened anxiety is associated with greater coping oriented substance use behavior in substance use disorders [43]

\section{Socioeconomic status of the studied adolescents:}

Regarding socioeconomic level of the studied groups, there was no significant differences between patient group and control group $(p=0.066)$. In contrast to the current results, Hanson \& Chen [44] demonstrated that high socioeconomic status teens reported more cigarette, alcohol and drug use than low socioeconomic status teens. Financial resources were more predictive of substance use behaviors than family social status.
Also, El-Awady et al., [18] and Mohamed et al., [21] reported that half of the participants were from the middle socioeconomic level, this can be explained that teens from higher socioeconomic status backgrounds may feel safer experimenting with substances than lower socioeconomic status teens or may suffer from achievement pressures and isolation from adults leading to greater substance use behaviors [45].

\section{Perceived parenting of the studied adolescents:}

As regards paternal parenting style, fathers of the patient group were more rejecting than the fathers of the control group ( $p=0.002)$, this is in agreement with some studies that have found an association between rejection and regular use of alcohol $[20,46]$.

Some international studies found that some parental practices (affection, rejection, and overprotection) have predictive value concerning substance use problems [47]

In contrast to the current results a study by Visser et al., [48] concluded that rejection was not associated with alcohol use during adolescence although the difference in findings regarding the influence of emotional warmth and rejection on alcohol use can be explained by the influence of alcohol-specific parenting.

As regards the scores of inconsistency-consistency of paternal parenting, the fathers of patients showed significantly higher consistency with their sons $(p=0.021)$.

But in contrast to our study, Effat et al., [20] found that fathers of cases were more inconsistent than fathers of control group.

Also Bates et al., [49] found that negative parenting (e.g. inconsistent and harsh discipline, low warmth, and monitoring) is positively associated with substance use disorders, and that positive parenting (e.g. positive reinforcement, acceptance, approval, and guidance) is negatively associated with addiction problems.

This discrepancy between results can be explained from the point of view that the fathers of patients were not only consistent but also were not flexible or authoritarian. This is in concordance with Hayes et al., [50] who reported that authoritarian parenting is associated with greater adolescent rebellion, which in turn is related to alcohol use. 
A recent review showed that most studies found that authoritative parenting was associated with the best outcomes as regards adolescent substance use, and neglectful parenting with the worst outcomes [51].

Children of authoritarian parents generally report more substance use compared with children of authoritative parents, but some studies found no difference or even an inverse association [51].

Findings related to the permissive parenting style are mixed; some studies have shown that permissive parenting is associated with higher rates of substance use, whereas others demonstrate the opposite association [18]

Unexpectedly the mothers of patients showed more significant independence in their parenting style $(p=0.005)$, although independence is considered a positive way of parenting and it is common for adolescents to seek it [52].

This is in agreement with the findings of the study of Effat et al., [20] who reported that mothers of cases showed more independence $(p=0.039)$. This independence has positive outcomes for many adolescents, but for those at risk for participation in problem behaviors, greater independence could be associated with negative outcomes [53].

Researchers also reported that parental love and positive expression is related with low levels of substance use disorders in adolescents [53] .

\section{Peer attachment of the studied adolescents:}

While the sores of both trust $(t=2.69, p=0.009)$ and communication $(t=3.48, p=0.001)$ are significantly higher in the control group than patients and there was no significant difference between both groups as regards alienation. So, the control group has more secure attachment with their peers than the patients. Trustful relationship and good communication between peers are protective factors against substance abuse. The role of peers in substance use disorders was however somewhat more ambiguous, including both positive and negative associations with substance use [54]

In contrast to some previous studies Long et al., [55] found that supportive relationships with friends were associated with increased risk of smoking, drinking and drug use, though not subjective wellbeing and mental health.

Feder et al., [56] found a link between delinquent peer behavior and substance use. Peer delinquency has been shown to mediate treatment effects on other delinquent behaviors [56].

Positive peer influence showed moderate negative correlations with indices of substance use and problematic substance use behaviors, this finding suggests that the more positive peer support adolescents have, the less they might engage in substance use [57].

Patients has significantly more friend with history of substance use disorders $(50 \%)$ versus (22.5\%) for control group ( $p=0.011)$.

Gaviria and Raphael [58] examined peer influence on substance use in peer groups in school and found prediction levels at $32 \%$ for illicit drugs and $35 \%$ for alcohol. Lundborg [59] found that the substance-using behaviors of peers significantly predicted binge drinking in adolescents (28\% to $47 \%)$.

\section{Conclusion:}

Substance use is more common in males than females. Adolescents with manual works are more susceptible to substance use disorders. Education is protective against substance use disorders. Adolescents from single parent families are more susceptible to substance use disorders than adolescents from nuclear families. Adolescents with positive family history of substance use disorders and family history of psychiatric disorders are more susceptible to substance use disorders. There are certain psychiatric disorders associated with substance use such as conduct disorder and depression. There are also some psychological factors associated with substance use disorder such as impulsivity, hopelessness and sensation seeking. Poor family management practices and relationships to peers using illicit drugs are important risk factors for addiction.

\section{Acknowledgments:}

This research was carried out without funding. We thank the cooperative persons, who accepted to participate in this study and gave of their time to finish the interview voluntarily and their care givers.

\section{Conflicts of interest:}

No conflicts of interest declared.

\section{Authors' contributions:}

All authors had equal role in design, work, statistical analysis and manuscript writing. All authors have approved the final article work. 


\section{References}

1- SMART R.G., HUGHES P.H., JOHNSTON L.D., ANU MONYE A., KHANT U., MEDINA MORA M.E., et al.: A methodology for student druguse surveys. Geneva: World Health Organization; 19, 2007.

2- World Health organisation: Global Status Report on Alcohol and Health. Geneva: WHO Zernicke KA, Cantrell H, Finn PR, Lucas J (2010); The association between earlier age of first drink, disinhibited personality, and externalizing psychopathology in young adults. Addict Behav., 35: 414-8, 2011.

3- HERRMAN J.W.: The Teen Brain as a Work in Progress: Implications for Pediatric Nurses. Pediatric Nursing; Pitman 31, (Mar./Apr. 2005), 144-8, 2005.

4- TEICHMAN M. and KEFIR E.: The effects of perceived parental behaviors, attitudes, and substance-use on adolescent attitudes toward and intent to use psycho active substances. J. Drug. Educ., 30: 193-204, 2000.

5- VITARO F., BRENDGEN M. and TREMBLAY R.: Influence of dviant friends on delinquency: Searching for moderator variables. J. Abnorm. Child. Psychol., 28: 31325, 2000.

6- KOKKEVI A.E., ARAPAKI A.A., RICHARDSON C., FLORESCU S., KUZMAN M. and STERGAR E.: Further investigation of psychological and environmental correlates of substance use in adolescence in six European countries. Drug and Alcohol Dependence, 88: 308-12, 2007.

7- KRANK M., STEWART S., O'CONNOR R., et al.: Structural, concurrent, and predictive validity of the Substance Use Risk Profile Scale in early adolescence. Addictive Behaviors Volume 36, Issues 1-2, January-February, Pages 37-46, 2011.

8- MELINA FATSEAS, FUSCHIA SERRE, JOEL SWENDSEN and MARC AURIACOMBE: Effects of anxiety and mood disorders on craving and substance use among patients with substance use disorder: An ecological momentary assessment study. Drug and Alcohol Dependence Volume 187, 1 June 2018, Pages 242-8 S03768716(18) 30201-1, 2018.

9- ZULAUF C.A., SPRICH S.E., SAFREN S.A., et al.: The complicated relationship between attention deficit/ hyperactivity disorder and substance use disorders. Curr. Psychiatry Rep., 16: 436, 2014.

10- American Psychiatric Association (APA): Highlights of Changes from DSM-IV-TR to DSM-5. Washington, DC: American Psychiatric Association, 2013.

11-LI-TZY W.U., Sc.D., WILLIAM E. SCHLENGER, Ph.D., and DEBORAH M. GALVIN: The Relationship Between Employment and Substance Use Among Students Aged 12 to 17 Journal of Adolescent Health, 32: 5-15 Vol. 32, No. 1, 2003.

12- BACHMAN J.G., WADSWORTH K.N., O'MALLEY P.M., JOHNSTON L.D. and SCHULENBERG J.E.: Smoking, Drinking, and Drug Use in Young Adulthood: The Impacts of New Freedoms and New Responsibilities. Mahwah, NJ: Lawrence Erlbaum Associates Inc., 1997.

13- GAVIOLI A., MATHIAS T.A., ROSSI R.M. and OLIVEIRA M.L.: Risks Related to Drug Use among Male Con- struction Workers, Acta Paul Enferm., 27 (5): 471-8. DOI http://dx.doi.org/10.1590/19820194201400077, 2014.

14- MIKHAIL M.N., EISSA M.A., LABEEB S.A. and ABD EL-HAMID S.M.: The Psychological Aspects of Drug Addicts in Assiut Governorate. Ass. Univ. Bull. Environ. Res., 4 (2): October 2001.

15- CABAN-MARTINEZ A.J., SIERRA D. and RUANOHERRERIA E.C.: Substance Abuse Surveillance Among ConstructionWorkers: A Proof of Concept Alternative Approach. JOEM, Volume 60, Number 3, 2018.

16- HAMDI E., SABRY N., SEDRAK A., KHOWAILED A. and LOZA N.: Sociodemographic Indicators for Substance Use and Abuse in Egypt. J. Addiction Prevention, 4 (1): 8, 2016.

17- JOHNSTON L.D., O'MALLEY P.M., MIECH R.A., BACHMAN J.G. and SCHULENBERG J.E.: Monitoring the Future national survey results on drug use, 1975-2015: Overview, key findings on adolescent drug use. Ann Arbor: Institute for Social Research, The University of Michigan, 2015.

18- EL-AWADY S.A., ELSHESHTAWY E.A., ELBAHAEY W.A. and ELBORAIE O.A.: Impact of familial risk factors on the severity of addiction in a sample of Egyptian Adolescents Egyptian Journal of Psychiatry, 38: 70-8, 2017.

19- HeMOVICH V., LAC A. and CRANO W.D.: Understanding early-onset drug and alcohol outcomes among youth: The role of family structure, social factors, and interpersonal perceptions of use. Psychol. Health Med., 16: 249 67, 2011.

20- EFFAT S.M., AZZAM H.M.E., ELGHAMRY R.H., et al.: Parenting Styles and Psychological Correlates in a Sample of Egyptian Adolescents with Substance-use Disorders. Addictive Disorders \& Their Treatment, 15 (2): 52-60. doi: 10.1097 /adt. 00000000000 00081, 2016.

21- MOHAMED N.R., EL HAMRAWY L.G., SHALABY A.S., EL BAHY M.S. and ABD ALLAH M.M.: An epidemiological study of tramadol $\mathrm{HCl}$ dependence in an outpatient addiction clinic at Heliopolis Psychiatric Hospital. M.M.J., 28: 591-6, 2015.

22- SITNICK S., SHAW D. and HYDE L.: Precursors of Adolescent Substance Use from Early Childhood and Early Adolescence: Testing a Developmental Cascade Model. Dev. Psychopathol., 26 (1): 125-40, 2014.

23- ARMSTRONG D. and COSTELlO J.: "Community studies on adolescent substance use, abuse, or dependence and psychiatric co-morbidity". J. Consult. Clin. Psychol., 70 (6): 1224-39, 2002.

24- ABDOU A., SADEK M., AMER D., et al.: "Addictive profile in juvenile delinquents admitted to correctional institutions in relation to personality characteristics". Middle East Curr. Psychiatry, 19: 78-84, 2011.

25- GOLDSTEIN I., STROBER A., AXELSON D., et al.: Predictors of First Onset Substance Use Disorders during the Prospective Course of Bipolar Spectrum Disorders in Adolescents. J. Am. Acad. Child Adolesc. Psychiatry, 52 (10): 1026-37, 2013.

26- SALAH E.M., YAMAMAH G.A., MEGAHED H.S., et al.: Screening for depressive symptoms and their associated 
risk factors in adolescent students in South Sinai, Egypt. Life Science Journal, 10 (3), 2013.

27- RAO U. and CHEN L.: Neurobiological and Psychosocial Processes Associated with Depressive and SubstanceRelated Disorders in Adolescents. Current Drug Abuse Reviews, 1: 68-80, 2008.

28- GAMBLE S.A., CONNER K.R., TALBOT N.L., YU Q., TU X.M. and CONNORS G.J.: Effects of pre-treatment and post treatment depressive symptoms on alcohol consumption following treatment in Project MATCH. J. Stud. Alcohol Drugs, 71: 71-7, 2010.

29- HAMDAN-MANSOUR A.M., MAHMOUD K.F., AL SHIBI A.N. and ARABIAT D.H.: Impulsivity and Sensation-Seeking Personality Traits as Predictors of Substance Use Among University Students. Journal of Psychosocial Nursing and Mental Health Services, 56 (1): 57-63, 2018.

30- KIRISCI L., TARTER R., MEZZICH A. and VANYUKOV M.: Developmental trajectory classes in substance use disorder etiology. Psychol Addic. Behav., 21: 287-96, 2007.

31- MONTEROSSO J.R., ARON A.R., CORDOVA X., XU J. and LONDON E.D.: Deficits in response inhibition associated with chronic methamphetamine abuse. Drug Alcohol Depend, 79: 273-7, 2005.

32- De WIT H.: Impulsivity as a determinant and consequence of drug use: A review of underlying processes. Addiction Biol., 14: 22-31, 2009.

33- CHRISTMAN A.K., FERMO J.D. and MARKOWITZ J.S.: Atomoxetine, a novel treatment for attention-deficithyperactivity disorder. Pharmacotherapy, 24: 1020-36, 2004.

34- MILLER M.L., REN Y., SZUTORISZ H., WARREN N.A., TESSEREAU C., EGERVARI G., et al.: Ventral striatal regulation of CREM mediates impulsive action and drug addiction vulnerability. Molecular Psychiatry (2017) 00: 1-8, 2018.

35- JAFFEE W.B. and D'ZURILLA T.J.: Personality, problem solving, and adolescent substance use. Behavior Therapy, 40 (1): 93-101. doi: 10.1016/j.beth.2008.03.001, 2009.

36- MALMBERG M., OVERBEEK G., MONSHOUWER K., LAMMERS J., WILMA A.M., VOLLEBERGH, RUTGER C.M.E. and ENGELS: Substance use risk profiles and associations with early substance use in adolescence J. Behav. Med., 33: 474-85, Doi 10.1007/s10865-0109278-4, 2010.

37- REINHERZ H.Z., PARADIS A.D., GIACONIA R.M., STASHWICK, C.K. and FITZMAURICE G.: Childhood and adolescent predictors of major depression in the transition to adulthood. American Journal of Psychiatry, 160: 2141-7, 2003.

38- SADEK G., CERNOVSKY Z. and CHIU S.: Hopelessness Scores and Urine Tests in Patients with Methadone Maintenance Therapy. Int. J. High Risk Behav. Addict., 7 (1): e67612, 2018.

39- COMEAU N., STEWART S.H. and LOBA P.: The relations of trait anxiety, anxiety-sensitivity, and sensation seeking to adolescents' motivations for alcohol, cigarette, and marijuana use. Addictive Behaviors, 26: 1-24, 2001.
40- SCHMIDT N.B., BUCKNER J.D. and KEOUGH M.E.: Anxiety sensitivity as a prospective predictor of alcohol use disorders. Behavior Modification, 31: 202-19, 2007.

41- CONROD P.J., PIHL R.O., STEWART S.H. and DONGIER M.: Validation of a system of classifying female substance abusers based on personality and motivational risk factors for substance abuse. Psychology of Addictive Behaviors, 14: 243-56. http://dx.doi. org/10.1037//0893164X.14.3.243, 2000.

42- STEWART S.H., SAMOLUK S.B. and MacDONALD A.B.: Anxiety sensitivity and substance use and abuse. In S. Taylor (Ed.), Anxiety sensitivity: Theory, research, and treatment of the fear of anxiety (pp. 287-3 19). Mahwah, NJ: Lawrence Erlbaum Associates, Inc. structures in two classrooms of Indian students. In G. Spindler (Ed.), 1999.

43- VUJANOVIC A.A., WARDLE M.C., BAKHSHAIE J., SMITH L.J., GREEN C.E., LANE S.D. and SCHMITZ J.M.: Distress tolerance: Associations with trauma and substance cue reactivity in low-income, inner-city adults with substance use disorders and posttraumatic stress. Psychology of Addictive Behaviors, 32, 3, 2018.

44- HANSON M. and CHEN E.: Socioeconomic status and substance use behaviors in adolescents, the role of family resources versus family social Status. Journal of Health Psychology, Vol. 12 (1): 32-5, 2007.

45- LUTHAR S.S. and LATENDRESSE S.J.: Children of the affluent: Challenges to well-being. Psychosomatic Medicine, 14: 49-53, 2005.

46- SHIN H., EDWARDS M. and HEEREN T.: Child abuse and neglect: Relations to adolescent binge drinking in the national longitudinal study of Adolescent Health (AddHealth) Study. Addict. Behav., 34: 277-80, 2009.

47- PRINZIE P., VAN DER SLUIS C.M., De HAAN A.D. and DEKOVIC'M.: The mediational role of parenting on the longitudinal relation between child personality and externalizing behavior. J. Pers., 78: 1301-23, 2010.

48- VISSER L., ANDREA F., WILMA A., et al.: The Impact of Parenting Styles on Adolescent Alcohol Use: The TRAILS Study. Eur. Addict. Res., 19: 165-72, 2013.

49- BATES J.E., PETTIT G.S. and DODGE K.A.: Family and child factors in stability and change in children's aggressiveness in elementary school. In McCord J. (Ed.), Coercion and punishment in long-term perspectives. New York: Cambridge University Press, 124-38, 1995.

50- HAYES L., SMART D., TOUMBOUROU J., et al.: Parenting influences on adolescent alcohol use [Project]. Melbourne: Australian Institute of Family Studies, 2004.

51- BECOÑA E., MARTÍNEZ Ú., CALAFAT A., JUAN M., FERNÁNDEZ-HERMIDA J.R. and SECADES-VILLA R.: Parental styles and drug use: A review. Drugs, 19: 110, 2015.

52- ECCLES J., WIGFIELD A. and BYRNES J.: "Cognitive development in adolescence". In: Lerner, RM.; Easterbrooks, MA.; Mistry, J., editors. Handbook of psychology: Developmental psychology. New York: Wiley; 6: 32550, 2003.

53- WALTHER C., CHEONG J., MOLINA B., et al.: Substance Use and Delinquency among Adolescents with Childhood ADHD: The Protective Role of Parenting. Psychol. Addict. Behav., 26 (3): 585-98, 2012. 
54- MOORE G.F., COX R., EVANS R.E., HALLINGBERG B., HAWKINS J., LITTLECOTT H.J., LONG S.J. and MURPHY S.: School, Peer and Family Relationships and Adolescent Substance Use, Subjective Wellbeing and Mental Health Symptoms in Wales: A Cross Sectional Study. Child Ind. Res., 30, 2018.

55- LONG, S.J., EVANS R.E., FLETCHER A., HEWITT G., MURPHYS., YOUNG H. and MOORE G.F.: Comparison of substance use, subjective well-being and interpersonal relationships among young people in foster care and private households: A cross sectional analysis of the school Health Research network survey in Wales. B.M.J. Open, 7 (2), 2017.

56- FEDER K.A., McCART M.R., KAHN G., MAURO P.M., SHEIDOW A.J. and LETOURNEAU E.J.: Association of Mental Health Symptoms and Peer Behaviors with
Risk for Substance Use and Condomless Sex Among Youths in Juvenile Drug Court, Journal of Child \& Adolescent Substance Abuse, Doi: 10.1080/10678 28X. 2018. 1430642, 2018.

57- COYLE C., BRAMHAM J., DUNDON N., MOYNIHAN M. and CARR A.: Exploring the Positive Impact of Peers on Adolescent Substance Misuse Journal of Child \& Adolescent Substance Abuse, 25 (2): 134-43. Doi: 10.1080/ 1067828X.2014.896761, 2016.

58- GAVIRIA A. and RAPHAEL S.: School-based peer effects and juvenile behavior. Review of Economics and Statistics, 83, 257268. Doi: 10.1162/00346530151143798, 2001.

59- LUNDBORG P.: Having the wrong friends? Peer effects in adolescent substance use. Journal of Health Economics, 25 (2): 214233. Doi: 10.1016/j.jhealeco.2005.02.001, 2006.

\title{
العوامل النفسية والإضطرابات الآسرية بين المراهقين المتعاطين للمخدرات
}

\author{
يعد تعاطى المواد المخدرة بين المراهقين مشكلة معقدة ومتعددة الآبعاد. تعد الصراعات الآسرية، وطرق التربية الخاطئة، والإنتماء إلى إلى

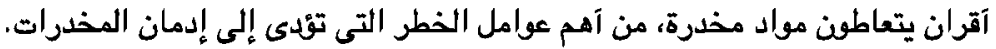 \\ الهدف من الدراسة: قياس الإندفاعية والعلاقة بالآصدقاء والمشاكل الآسرية بين العدمنين من المراهقين.

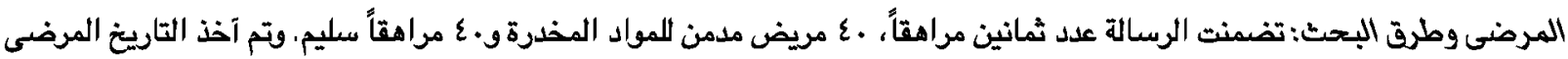

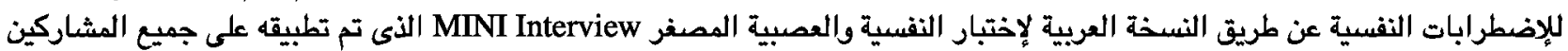

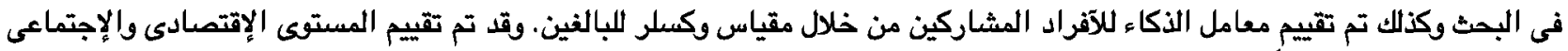

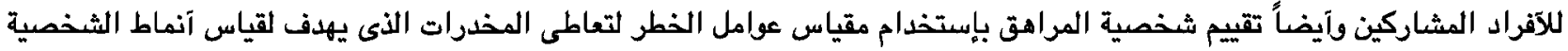

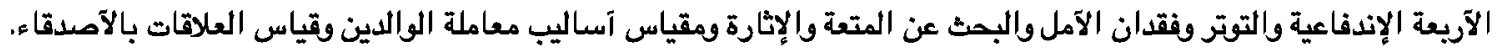

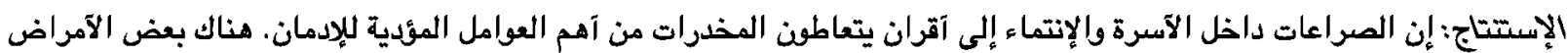

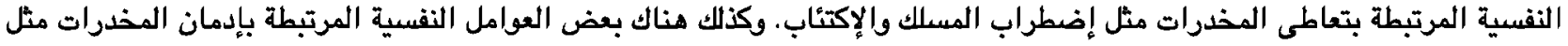 \\ |الإندفاعية. \\ التوصيات:نحن نوصى بضرودة عمل حملات توعية لأولياء الآمور بآساليب التربية الصحيحة وكذلك الكثف الدودى على المراهقين لتشخيص \\ الآمراض النفسية وعلاجها لتفادى عوامل الخطر المؤدية للإدمان.
}

